\title{
GRAPHITE, OR BLACK LEAD CRUCIBLES.
}

\author{
By J. С. Booth, Pн.D.
}

The use of graphite for pencils, stove blacking, lubricating surfaces, \&c., is extremely limited, compared with its enormous value and consumption in crucibles, employed in melting gold, silver, copper, brass, bronze, German silver, \&e., and especially in smelting the finest steel for tools, for the tires of locomotive driving wheels, and even for the ponderous shafts of the great ocean steamers; in short, wherever the finest quality of steel is demanded in the arts. Such steel being a marked expression of the physical power of civiliza. tion, the chief means of procuring the black lead crucible has the strongest claim on our attention.

In studying its manufacture $I$ shall successively consider, 1 . the materials employed; 2 . their preparation and mixture; 3 . the formation and completion of the crucible.

Matérials.-A black lead crucible is essentially composed of graphite or black lead ground to tin scales, which are rigidly held in their position by partially melted clay ground up with powdered graphite and a little sand, the last being added to prevent shrinkage while drying, and the dried crucible, made from this mixture, is finished by burning at a high heat.

Since black lead is virtually pure carbon, the question arises why might not the cheapest form of carbon, Anthracite, be substituted for it? Because of the difference in their mechanical structure and their behavior to heat.

All the forms of carbon combine with the oxygen of the air at a high heat, and gradually burn away into carbonic acid or oxide, but graphite burns much more slowly than any other form (except the diamond). Ali the forms except graphite, at a strong heat, below combustion, crackle into a fine, structureless powder, or are easily ground into powder, the particles of which have no property or means of cohesion, nor of adhesion to other bodies, and cannot therefore be made into a tough, coherent crucible.

Black lead has an eminently laminated, crystalline structure, breaking into thin scales, but not at right angles to their plane, for, however thin a piece may appear to the eye, it breaks into still thinner scales, of the same structure and toughness as the original. A single thin scale held in a delicate forceps shows a remarkable 
degree of elasticity, when bent, by springing back to its original position unaltered. Neither a low heat nor a white heat will make it exfoliate.

It appears, then, that the distinctive properties of graphite for crucibles are, that it retains the flat or scaly form, even under hard grinding, and at the bighest heats; that the scales are extremely elastic and tough, and that it resists combustion in the air much more than the ordinary forms of carbon.

Varieties of Graphite.-It occurs in three forms, the elastic laminated, the elastic fibrous, and the more amorphous variety. As the elastic fibrous variety may be used indifferently with the scaly, and is quite rare, we need not dwell upon it. I have termed the third form more amorphous, because it sometimes has the external appearance of the scaly variety, and does of ten contain some of it. A little experience will enable one to distinguish it by the eye, and a simple test will establish a more reliable estimate of value. A minute quantity, finely ground in a mortar, will approximately show the proportionate quantity of scaly and shapeless powder, and the conclusion may be strengthened by sifting it through a piece of fine muslin, when the eye can sufficiently determine the relative quantity of each. Since the amorphous variety, although deceptively crystalline in appearance, adds but little, if anything, to the strength of a crucible, the manufacturer should avoid its use as much as practicable. I think that my experience will bear me out in saying, that only at an enormous reduction in relative price, and even then only a small proportion of it, compared with the best scaly kind, will warrant the manufacturer of black lead crucibles in employing it, at the great risk of his reputa. tion, for the best black lead crucible.

Commercial graphite occurs as "lump-lead," "grains" and "dust." During some years' experience in making black lead crucibles, I found that by far the greater part of the graphite of commerce consisted of the excellent scaly variety, whether in lump or grains, and therefore giving no pretext for using inferior graphite, except the unsoundness of false economy. I found a barrel entirely filled by one piece of the best Ceylon graphite, and single lumps of several pounds weight each, are of frequent occurrence and of the best quality. A few of the smaller lumps, up to $\frac{1}{2} \mathrm{lb}$. weight, are of the deceptive amorphous variety, which is, however, more of ten present in the fine powder with an iron black, lustreless appearance. Graph- 
ite in clean, sifted grains, free from powder, is generally of excellent quality. The best variety has a silvery lustre, the next lower grade, although it may be of fair quality, has a bright, steel lustre, and the lower the grade the more it puts on an iron black, or sometimes a brownish tint.

I have found the impurity of ground commercial lump lead of the best quality to be about 6 per cent., and to consist chiefly of quartz and iron pyrites. On the other hand, I have seen silvery graphite in grains of the uniform size of about $\frac{1}{8}$ inch, and without dust, which was almost absolutely pure carbon.

Localities.-Graphite is abundantly distributed in metamorphic rocks, but rarely in large masses together. Many localities have been explored with a view to its use for crucibles, but almost all were successively abandoned, because of the excessive cost of extraction, and in a few cases because of its inferior quality.

The island of Ceylon contributes the great mass of black lead to commerce; 14,000 tons hiaving been shipped from it in 1883 . Most fortunate is it that nearly all of it is of the best quality.

We find small quantities of it sparingly distributed in all the states of the Union and in every country on the globe where met. amorphic influences have imparted a crystalline structure to the lower geological formations. It has been extracted at several different times [from the locality in Philadelphia, Penn., within ten miles of the centre of the eity, and with partial success. The quality is good, but lacks mass in loco.

When called upon to explore the locality, I took the bearing of the adjacent gneiss, \&c., and, applying it to the shaft which struck the graphite, I found it pointed exactly to the various openings from which the latter had been extracted. The rocks in contact with and containing the graphite, are so highly metamorphosed and confused with crystallization, that the planes of stratification are only recognizable by experience. Since the rocks are stratified, they were once deposited sands and clays, with the remains of plants that grew on them, condensed and modified into coal, which probably passed through the changes of lignite, bituminous coal and anthraeite into graphite.

(To be continued.) 